\section{Attitudes of surgeons toward the treatment and prosthetic rehabilitation of oral cancer patients - A questionnaire survey in central India}

KEY WORDS: Prosthetic

Rehabilitation, Surgical

Reconstruction, Multidisciplinary Team Approach, Oral Cancer Patients

\section{Baban Kudwe*}

Sattyam Wankhade

\section{Arun Khalikar}

\section{Suryakant Deogade}

\section{Almas Shaikh}

Postgraduate student, Department of Prosthodontics, Government Dental College and Hospital, Nagpur. *Corresponding Author

Associate Professor, Department Of Prosthodontics, Government Dental College And Hospital, Nagpur

Professor, Department Of Prosthodontics, Government Dental College And Hospital, Nagpur

Associate Professor, Department of Prosthodontics, Government Dental College and Hospital, Nagpur

Postgraduate student, Department of Prosthodontics, Government Dental College and Hospital, Nagpur

AIM: To investigate the knowledge and attitude of surgeons toward the treatment and prosthetic rehabilitation of cancer patients in central India

SETTINGS AND DESIGN: Descriptive survey

MATERIALS AND METHODS: The survey was conducted by a printed questionnaire with 13 close-ended questions, distributed among 80 surgeons from different specialities practicing in different locations of central India. The responses were collected by personal visits to the participants and analysed.

RESULTS: Approximately more than one-half (67.5\%) of the participants performed maxillary resections, and only $19.2 \%$ of the participants surgically reconstructed the maxillary defects in $75-100 \%$ of the treated cases. Furthermore, although all the participating surgeons believed in a multidisciplinary team approach and dental rehabilitation following surgical reconstructions, only $64 \%$ of them obtained pre-surgical dental evaluations from a prosthodontist. Moreover, although $97.5 \%$ of them communicated with a prosthodontist for prosthetic rehabilitation, only $2.5 \%$ of them got almost all their cases rehabilitated with a definitive prosthesis.

CONCLUSION: The current practice trends of the surgeons in central India dealing with oral cancer patients indicate that although having a belief in a multidisciplinary team approach, the surgeons for some reasons have being exhibiting reluctance toward accessing the services of a prosthodontist and prosthetic rehabilitation of the treated oral cancer patients.

\section{INTRODUCTION}

Many oral cancer patients undergo surgical resections of malignant tumours and thereby suffer from acquired surgical defects. Although the defects can be managed either by a surgical reconstruction or a prosthetic rehabilitation, the decision of choosing any of the two modalities is multifactorial and requires a multidisciplinary team approach. ${ }^{[1-3]} \mathrm{A}$ surgeon's attitude toward accessing the services of a prosthodontist for pre-surgical evaluation and his/her belief in a multidisciplinary team approach is one of the crucial factors influencing the decision on whether to reconstruct the defect surgically or rehabilitate it with a prosthesis. ${ }^{[4]}$

Globally, many national clinical guidelines have been formulated that outline the need of a prosthodontist to be a part of the multidisciplinary team in the management of patients with head and neck cancers. . $^{[5,6]}$

The present study was designed to evaluate the attitudes of surgeons in central India regarding the treatment and prosthetic rehabilitation in patients with oral cancer undergoing maxillary resections and their beliefs in a multidisciplinary team approach and accessing the services of a prosthodontist pre-and post-surgically.

\section{MATERIALS AND METHODS}

A questionnaire survey was designed in the English language to assess the attitudes of surgeons toward the treatment and prosthetic rehabilitation of oral cancer patients undergoing maxillary resections. The survey was conducted by distributing printed copies of the questionnaire among surgeons from different specialities such as dentistry and maxillofacial, plastic, general and ENT surgery, at different locations in central India. A total of 80 surgeons willingly responded the survey.

The created questionnaire composed of 13 close-ended questions with a beginning statement addressing the aim of the survey (Table 1). All questions were marked mandatory with only one response allowed to be chosen for every question. The completion of survey required a period of two weeks in the month of January 2020. The responses were collected on the printed copies of the questionnaire by personal visits by the authors to the participating surgeons.

The collected data was represented in counts and percentages and the results were statistically analyzed using the Chi-square test. The data were analyzed using the Statistical Package for the Social Sciences statistical software (IBM SPSS Statistics for Windows, Version 20.0. IBM Corp., Armonk, NY,USA).

Table 1: Questionnaire concerning the attitudes of surgeons towards treatment and prosthetic rehabilitation of oral cancer patients along with the statistical analysis of the responses

\begin{tabular}{|c|c|c|c|}
\hline Questions & \multicolumn{2}{|c|}{ Choice of responses } & p value \\
\hline \multirow{2}{*}{$\begin{array}{c}\text { Sector in which you } \\
\text { practice }\end{array}$} & Government & Private & 0.074 \\
\cline { 2 - 4 } & $32(40 \%)$ & $48(60 \%)$ & \\
\hline
\end{tabular}


PARIPEX - INDIAN JOURNAL OF RESEARCH | Volume - 9 | Issue - 9 | September - 2020 | PRINT ISSN No. 2250 - 1991 | DOI : $10.36106 /$ paripex

\begin{tabular}{|c|c|c|c|c|c|c|}
\hline \multirow[t]{2}{*}{$\begin{array}{l}\text { Speciality of } \\
\text { practice }\end{array}$} & ENT surgery & Plastic surgery & General surgery & $\begin{array}{c}\text { Oral and } \\
\text { maxillo-facial } \\
\text { surgery }\end{array}$ & $\begin{array}{l}\text { General } \\
\text { dentistry }\end{array}$ & \multirow[t]{2}{*}{0.157} \\
\hline & $26(32.5 \%)$ & $0(0 \%)$ & $34(42.5 \%)$ & $20(25 \%)$ & $0(0 \%)$ & \\
\hline \multirow{2}{*}{$\begin{array}{c}\text { Do you perform } \\
\text { maxillary } \\
\text { resections? }\end{array}$} & \multicolumn{3}{|c|}{ Yes } & \multicolumn{2}{|c|}{ No } & \multirow[t]{2}{*}{$0.002 *$} \\
\hline & \multicolumn{3}{|c|}{$54(67.5 \%)$} & \multicolumn{2}{|c|}{$26(32.5 \%)$} & \\
\hline \multirow{2}{*}{$\begin{array}{c}\text { How many patients } \\
\text { do you treat in a } \\
\text { year? }\end{array}$} & Less than 10 & \multicolumn{2}{|c|}{ Between 10-15 } & Between 16-30 & Over 30 & \multirow[t]{2}{*}{$<0.001 * *$} \\
\hline & $14(17.5 \%)$ & \multicolumn{2}{|c|}{$11(13.8 \%)$} & $1(13.8 \%)$ & $44(55 \%)$ & \\
\hline \multirow{2}{*}{$\begin{array}{l}\text { Do you perform } \\
\text { surgical } \\
\text { reconstruction of } \\
\text { the maxillary } \\
\text { defect? }\end{array}$} & \multicolumn{3}{|c|}{ Yes } & \multicolumn{2}{|c|}{ No } & \multirow[t]{2}{*}{$<0.001 * *$} \\
\hline & \multicolumn{3}{|c|}{$78(97.5 \%)$} & \multicolumn{2}{|c|}{$2(2.5 \%)$} & \\
\hline \multirow{2}{*}{$\begin{array}{c}\text { What percentage of } \\
\text { cases is surgically } \\
\text { reconstructed? }\end{array}$} & $0-25 \%$ & \multicolumn{2}{|c|}{$25-50 \%$} & $50-75 \%$ & $75-100 \%$ & \multirow[t]{2}{*}{$0.028 *$} \\
\hline & $31(39.7 \%)$ & \multicolumn{2}{|c|}{$16(20.5 \%)$} & $16(20.5 \%)$ & $17(19.2 \%)$ & \\
\hline \multirow{2}{*}{$\begin{array}{l}\text { Do you believe in } \\
\text { multidisciplinary } \\
\text { team clinic? }\end{array}$} & \multicolumn{3}{|c|}{ Yes } & \multicolumn{2}{|c|}{ No } & \multirow[t]{2}{*}{1.000} \\
\hline & \multicolumn{3}{|c|}{$80(100 \%)$} & \multicolumn{2}{|c|}{$0(0 \%)$} & \\
\hline \multirow{2}{*}{\begin{tabular}{|c|} 
If yes, which \\
speciality do you \\
prefer to involve in \\
your \\
multidisciplinary \\
team? \\
\end{tabular}} & ENT surgery & Plastic surgery & General surgery & $\begin{array}{c}\text { Oral and Maxillo- } \\
\text { facial surgery }\end{array}$ & $\begin{array}{c}\text { General } \\
\text { Dentistry }\end{array}$ & \multirow[t]{2}{*}{$0.004 *$} \\
\hline & $15(18.8 \%)$ & $22(27.5 \%)$ & $8(10 \%)$ & $9(11.2 \%)$ & $26(32.5 \%)$ & \\
\hline \multirow{2}{*}{$\begin{array}{c}\text { Do you refer your } \\
\text { treated patients for } \\
\text { a multidisciplinary } \\
\text { team approach? }\end{array}$} & \multicolumn{3}{|c|}{ Yes } & \multicolumn{2}{|c|}{ No } & \multirow[t]{2}{*}{$<0.001 * *$} \\
\hline & & $66(82.5 \%)$ & & $14(17$ & $\%)$ & \\
\hline Do you obtain a & & Yes & & $\mathrm{Nc}$ & & $<0.001 * *$ \\
\hline $\begin{array}{c}\text { pre-surgical dental } \\
\text { evaluation from a } \\
\text { prosthodontist? }\end{array}$ & & $64(80 \%)$ & & $16(2)$ & & \\
\hline Do you believe in & & Yes & & $\mathrm{Nc}$ & & 1.000 \\
\hline $\begin{array}{c}\text { dental rehabilitation } \\
\text { following surgical } \\
\text { reconstruction? }\end{array}$ & & $80(100 \%)$ & & $0(0$ & & \\
\hline Do you & & Yes & & $\mathrm{Nc}$ & & $<0.001 * *$ \\
\hline $\begin{array}{c}\text { communicate with a } \\
\text { prosthodontist for } \\
\text { prosthetic } \\
\text { rehabilitation? }\end{array}$ & & $78(97.5 \%)$ & & $2(2.5$ & & \\
\hline What percentage of & $0-15 \%$ & 16 & $0 \%$ & $51-75 \%$ & $76-100 \%$ & $<0.001 * *$ \\
\hline $\begin{array}{c}\text { cases is } \\
\text { rehabilitated with a } \\
\text { definitive } \\
\text { prosthesis? }\end{array}$ & $29(36.2 \%)$ & 16 & $0 \%)$ & $33(41.2 \%)$ & $2(2.5 \%)$ & \\
\hline
\end{tabular}

\section{p $>0.05-$ no significant difference $* p<0.05-$ significant difference $* * p<0.001-$ highly significant}

\section{RESULTS}

A total of 80 surgeons responded to the questionnaire. Sixty percent of the respondents practiced in private sector and $40 \%$ in government sector. Most of the respondents were general surgeons (34), followed by ENT (26) and oral and maxillofacial surgeons (20), and none of them was from the speciality of plastic surgery or general dentistry.

Approximately, more than one-half $(67.5 \%(54 / 80))$ of the respondents performed maxillary resections; $55 \%$ (44/80) of them treating 30 patients per year and $17.5 \%$ (14/80) treating less than 10 patients per year.

More than one-third of the respondents (97.5\% (78/80)) performed surgical reconstruction of the maxillary defects; however, only $19.2 \%(17 / 80)$ of the respondents reconstructed the maxillary defects in $75-100 \%$ of the treated cases.

All the $80(100 \%)$ respondents believed in the idea of a multidisciplinary team; however, only $82.5 \%$ (66/80) of them referred their patients toward a multidisciplinary team approach. Furthermore, maximum number of the respondents preferred general dentistry $(32.5 \%(26 / 80))$ and plastic surgery $(27.5 \%(22 / 80))$ as the specialities to be a part of the multidisciplinary team.

Although, all the $80(100 \%)$ respondents believed in dental rehabilitation following surgical reconstruction, only $80 \%$ $(64 / 80)$ of them obtained a pre-surgical dental evaluation from a prosthodontist and $20 \%(16 / 80)$ took decisions on their own. Moreover, although $97.5 \%$ (78/80) of the respondents communicated with a prosthodontist for prosthetic rehabilitation, only $2.5 \%(2 / 80)$ of them rehabilitated almost all their cases with a definitive prosthesis.

\section{DISCUSSION}

Oral cancer patients face immense psychological stress apart from physical agony due to the surgical defects and disfigurement caused by massive surgeries undertaken for 
the malignancies. ${ }^{[8,9]}$ The decision to either surgically reconstruct or prosthetically rehabilitate a surgical defect is dependent on numerous factors, including the surgeons' own preferences. ${ }^{[4]}$

The present study illustrated the knowledge and attitude of surgeons toward the prosthetic rehabilitation in patients surgically treated for oral cancers. A similar study was previously conducted by Alani A et al. in UK. They conducted a national survey of oral and maxillofacial surgeons' attitudes toward the treatment and dental rehabilitation in cancer patients and highlighted the changes in the dental rehabilitation of the patients undergoing maxillofacial surgeries, especially the maxillectomy procedures. ${ }^{[7]}$ Although, globally, many implemented clinical guidelines state that a restorative dentist needs to be a member of the multidisciplinary team, the survey conducted by Alani $A$ et al. reported that this was implemented among only $30 \%$ of the respondents. In the present survey, it was found that although all the surgeons believed in the idea of a multidisciplinary team approach, only $82.5 \%$ of them referred their patients to a multidisciplinary team.

For the most effective post-surgical outcomes, the process of rehabilitation must preferably begin right at the moment of initial diagnosis and treatment planning. Conservation of the remaining sound natural teeth is an imperative asset in the rehabilitation of intraoral defects. ${ }^{[10]}$ This can be best accomplished by planning the case in co-ordination with an experienced and skilled prosthodontist. However, in our survey, although all the surgeons believed in dental rehabilitation following surgical reconstruction, only $80 \%$ of them obtained a pre-surgical dental evaluation from a prosthodontist.

Furthermore, although $97.5 \%$ of the surgeons communicated with a prosthodontist for prosthetic rehabilitation, only $2.5 \%$ of them rehabilitated almost all their cases with a definitive prosthesis.With a wide range of rehabilitative options that can be provided by a maxillofacial prosthodontist, a lack of communication or acceptance of their services is a barrier in delivering a better quality of life to the distressed surgically operated oral cancer patients.

Although, maxillofacial prosthetic treatment is not a substitute for plastic and reconstructive surgery, it may be a saviour alternative in certain circumstances. Few patients may not be good candidates for plastic surgery owing to various debilitating factors such as advanced age, poor health and impermissible type of deformity or poor blood supply to irradiated tissues. However, prosthetic treatment poses the best possible alternative when anatomical parts are not replaceable by living tissues and when recurrence is likely or when radiotherapy is being administered. Furthermore, prosthetic rehabilitation has specific advantages such as requirement of little or no additional surgery and results often being more than or as aesthetically pleasing as those obtained by surgical reconstructions. Additionally, patients after already undergoing massive surgeries for malignancies, tend to resort to less traumatic or drastic procedures for rehabilitation. Thus, prosthetic rehabilitation scores higher at being chosen by the patients over plastic surgeries. ${ }^{[10]}$

Lastly, a prosthodontist apart from rehabilitation extends his/her responsibilities toward ensuring adequate preparation of the oral cavity at reducing potential untoward effects of cancer treatment, educating the patients about the possible short-term and long-term complications and training them in oral hygiene methods and therapeutics for the best possible preservation of oral and general wellbeing. Moreover, long-term follow-up, with a high degree of vigilance on the possibility of recurrence, delivers a crucial contribution of prosthodontists toward the lives of cancer patients.[11]

\section{CONCLUSIONS}

Base on the present survey, the following conclusions were drawn:

1. In the current practice, only $80 \%$ of the surgeons in central India access the prosthodontists for prosthetic rehabilitation in cancer patients.

2. Although all the surgeons believe in a multidisciplinary team approach, only $82.5 \%$ of them refer their patients to the team and most of them prefer plastic surgery and general dentistry as the specialities to be included in the team.

3. Despite believing in the importance of dental rehabilitation after surgical reconstruction and having communications with prosthodontists for prosthetic rehabilitations of surgical defects, the surgeons for some reasons exhibit reluctance toward accessing the services of a prosthodontist for pre-surgical dental evaluations and prosthetic rehabilitation of the treated oral cancer patients.

Further extensive surveys to evaluate the attitudes of surgeons toward the prosthetic rehabilitation of oral cancer patients, spread of awareness regarding the crucial role of prosthodontist in the management of such patients and an assessment of the evolution of the beliefs of the surgeons in the coming years are needed to be undertaken sincerely.

\section{Financial support and sponsorship: Nil}

\section{Conflicts of interest: There are no conflicts of interest}

\section{REFERENCES}

1. Friedman E, Friedman C. Tumours of the head and neck. A 4-year study of a multidisciplinary approach. Int J Oral Surg 1978;7:291-295.

2. King G E, Lemon J C, Martin JW. Multidisciplinary teamwork in the treatment and rehabilitation of the head and neck cancer patient. Tex Dent J 1992;109:9-12.

3. Okay D J, Genden E, Buchbinder D, Urken M. Prosthodontic guidelines for surgical reconstruction of the maxilla: a classi cation system of defects. J Prosthet Dent 2001;86(4):352-363.

4. Ali A, Fardy M J, Patton DW. Maxillectomy - to reconstruct or obturate? Results of a UK survey of oral and maxillofacial surgeons. Br J Oral Maxillofac Surg 1995;33:207-210.

5. Guidance on Cancer Services Improving Outcomes in Head and Neck Cancers The Manual National Institute for Clinical Excellence. Guidance on cancer services: Improving outcomes in head and neck cancers: the manual. London:NICE, 2004

6. Scottish Intercollegiate Guidelines Network. Diagnosis and management of head and neck cancer: a national clinical guideline. Edinburgh:SIGN, 2006.

7. A. Alani, J. Owens, K. Dewan, A. Summerwill. A national survey of oral and maxillofacial surgeons' attitudes towards the treatment and dental rehabilitation of oral cancer patients. British Dental Journal 2009;207:E2 1 .

8. Vidhubala E, Latha, Ravikannan R, Mani CS, Karthikesh M. Coping preferences of head and neck cancer patients - Indian context. Indian J Cancer. 2006;43:6-11.

9. Arunachalam D, Thirumoorthy A, Devi S, Thennarasu Quality of life in cancer patients with disfigurement due to cancer and its treatments. Indian J Pallia Care. 2011;17:184-90.

10. Mantri S, Bhasin A, Shankaran G, Gupta P. Scope of prosthodontic services for patients with head and neck cancer, Indian J Cancer 2012;49:39-45.

11. Patton D W, Ali A, Davies R, Fardy M J. Oral rehabilitation and quality of life following the treatment of oral cancer. Dent Update 1994;21:231-234. 